\title{
Determinants of consumer intention to purchase animal-friendly milk
}

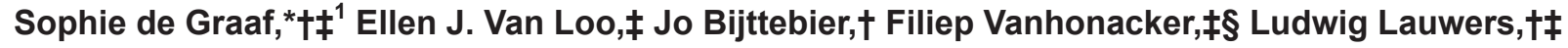 \\ Frank A. M. Tuyttens, ${ }^{*}$ and Wim Verbekeł \\ *Animal Sciences Unit, Institute for Agricultural and Fisheries Research (ILVO), Scheldeweg 68, 9090 Melle, Belgium \\ †Social Sciences Unit, Institute for Agricultural and Fisheries Research (ILVO), Burg. Van Gansberghelaan 115, 9820 Merelbeke, Belgium \\ ‡Department of Agricultural Economics, Faculty of Bioscience Engineering, Ghent University, Coupure links 653 , 9000 Ghent, Belgium \\ §Faculty of Bioscience Engineering, Department of Applied Biosciences, Ghent University, V. Vaerwyckweg 1, 9000 Ghent, Belgium
}

\section{ABSTRACT}

Concern about the welfare of production animals is growing among various stakeholders, including the general public. Citizens can influence the market for premium welfare products by expressing public concerns, and consumers - the actors who actually purchase products - can do so through their purchasing behavior. However, current market shares for premium welfare products are small in Europe. To better align purchase behavior with public and individuals' concerns, insight is needed into determinants that influence the intention to purchase premium welfare products. A cross-sectional online survey of 787 Flemish milk consumers was conducted to investigate attitudes toward and intention to purchase animal-friendly milk. More than half of the sample (52.5\%) expressed the intention to purchase animal-friendly milk. Linear regression modeling indicated that intention was positively influenced by (1) higher perceived product benefits from animal-friendly milk (milk with more health benefits and higher quality); (2) higher personal importance of extrinsic product attributes such as local production and country of origin; (3) higher personal importance of animal welfare; (4) a more natural living oriented attitude toward cows; and (5) a more positive general attitude toward milk. Intention was negatively influenced by (1) a stronger business-oriented attitude toward cows; and (2) by a higher personal importance attached to price. These insights in key components of purchase intention can assist producers, the dairy industry, and retailers to position and market animal-friendly milk.

Key words: consumer, survey, dairy produce, animal welfare

Received January 12, 2016.

Accepted June 17, 2016.

${ }^{1}$ Corresponding author: sophie.degraaf@ilvo.vlaanderen.be

\section{INTRODUCTION}

A diverse group of stakeholders, including citizens, farmers, public authorities, and the food industry, is increasingly confronted, interested, or concerned with the welfare of production animals (Verbeke, 2009). Many studies related to this topic have focused on the end user of the chain, both in their role as citizen and consumer. The public can influence the marketing and sale of premium welfare products by acting as citizens (influencing government policy by expressing existing public concerns) and as consumers (choosing to purchase certain products instead of others).

Results from both citizen and consumer studies illustrate a sense of public concern about farm animal welfare (e.g., Serpell, 2004; Mejdell, 2006; European Commission, 2016) and a positive intention to purchase premium welfare products expressed in terms of selfreported willingness to pay (e.g., Taylor and Signal, 2009; Vanhonacker and Verbeke, 2009; Van Loo et al., 2013, 2014). However, current market shares for premium welfare products are small in European Union (EU) countries [e.g., a market share for organic milk of $2.7 \%$ in Belgium in 2015 (Samborski and Van Bellegem, 2016)], which does not reflect citizens' stated valuation of animal welfare (European Commission, 2016). Several reasons are suggested for this citizen/ consumer duality: limited (perceived) product availability (Vermeir and Verbeke, 2006), inadequate information provisioning (Harper and Henson, 2001; Verbeke, 2005), other product attributes (quality, food safety, price) that outweigh animal welfare in the purchasing decision (Heleski et al., 2004; Ingenbleek et al., 2006; Vanhonacker and Verbeke, 2014), and a lack of differentiation among products in terms of the level of animal welfare (de Jonge and van Trijp, 2013, 2014). The lack of differentiation refers to the products currently available, which are mainly either conventional or organic (Oosterkamp et al., 2011; de Jonge et al., 2015). Organic products in EU member states follow the rules set out in the EU Council Regulation (EC) No. 834/2007 and include conditions which citizens generally associ- 
ate with enhanced welfare such as permanent access to open air areas (preferably pasture). These organic products mainly target a niche market that is willing and able to pay (high) price premiums. Other consumer segments consider animal welfare as an important product attribute but not to a degree that they are willing to pay double or more for such products (Grunert et al., 2004; Vanhonacker et al., 2007). These segments are left with an unmet preference and purchasing desire. Better alignment of purchase behavior with individuals' concerns and preferences can be supported by insight into determinants that influence intention to purchase premium welfare products.

According to the theory of planned behavior (TPB; Ajzen, 1985), the intention to perform a certain behavior precedes the actual behavior. Ajzen suggested 3 factors that determine intention: attitudes, subjective norms and perceived behavioral control. This study focuses on the relationship between attitudes and intention. Fishbein and Ajzen (2010, p. 76) defined an attitude as "a latent disposition or tendency to respond with some degree of favorableness or unfavorableness to a psychological object."

Previous studies have mainly focused on attitudes in relation to general farm animal welfare (e.g., Austin et al., 2005; Taylor and Signal, 2009; Vanhonacker et al., 2010). However, participants experience different degrees of "feeling well-informed about the welfare" of various farm animal species (Harper and Henson, 2001) and experience different types and levels of concerns for the welfare of different species (Harper and Henson, 2001; European Commission, 2007). In this perspective, a species-specific approach is relevant and adds to the existing knowledge. The present study focuses on dairy cows for the following reasons. First, a large diversity of farm management practices can be found within the dairy sector that influence animal welfare [for instance, pasturing versus zero grazing; tied housing, free stalls, or deep litter (von Keyserlingk et al., 2012; de Vries et al., 2015)]. This diversity makes it possible to differentiate between products based on the characteristics of the production system. Second, milk is produced by cows without these having to be killed. This facilitates the provision of product information related to the animal and its welfare, more so than in meat as consumers do not want to be reminded of the living animal and that it had to be killed for the product when purchasing meat (e.g., Holm and Møhl, 2000; te Velde et al., 2002; Kennedy et al., 2004; Buller and Cesar, 2007).

The aim of this study was to gain insight into the influence of attitudes, perceptions of product-related factors, and milk consumption on intention to purchase animal-friendly milk. Based on a theory explaining hu- man behavior (Ajzen, 1985), we hypothesize that the attitudinal determinants of the intention to purchase animal-friendly milk are attitude toward milk, attitude toward the milk industry, and attitude toward dairy cows. Additionally, we will examine the role of product attribute importance and associations between animal welfare and other product attributes, because of their potential effect on purchasing decisions in the case of animal-friendly products.

\section{MATERIALS AND METHODS}

\section{Data Collection and Sample}

Quantitative descriptive data were collected through a cross-sectional survey using a sample representative for age (20-65 yr), sex, education, and region $(\mathrm{n}=787)$ from Flanders (the northern region of Belgium; Table 1). All participants were to some extent involved in food purchasing and purchased milk at least once a month (inclusion criteria). Participants were selected from a panel from a professional market research agency. All contact and questionnaire administration procedures were managed electronically. All data were collected during March to May 2014.

\section{Questionnaire}

The questionnaire assessed consumers' intention to purchase animal-friendly milk, socio-demographics (age, sex, education, and region), milk consumption frequency, milk types bought, attitudes toward dairy cows, general attitudes toward milk and the milk industry, associations between animal welfare and other product attributes, and importance of product attributes when purchasing milk.

Intention to Purchase, Milk Consumption Frequency, and Type. Consumers' intention to purchase animal-friendly milk was measured with the statement "I am willing to purchase animal-friendly milk from now on, instead of the milk I usually purchase," using a 5 -point Likert scale ranging from 1 = fully disagree to $5=$ fully agree.

Participants were asked how often they consume cow milk and which type of milk they usually purchase. Regarding frequency of milk consumption, participants could choose one of the following options: multiple times per day, every day, multiple times per week, once per week, less than once per week, or never. For the type of milk, the main types present in the Belgian market were listed, including organic [following Council Regulation (EC) No 834/2007], fair trade (indicates that farmers received a fair and higher price for their 
Table 1. Socio-demographic profile of the sample $(\mathrm{n}=787)$

\begin{tabular}{llc}
\hline Sample characteristics & & Frequency (\%) \\
\hline Age (yr) & $21-29$ & 17.5 \\
& $30-39$ & 23.1 \\
& $40-49$ & 24.7 \\
& $50-59$ & 21.9 \\
Regional distribution & $60-65$ & 12.9 \\
& Antwerp & 28.4 \\
& East Flanders & 23.9 \\
& West Flanders & 18.1 \\
Sex & Flemish Brabant & 15.2 \\
& Limburg & 14.4 \\
Education & Female & 52.4 \\
& Male & 47.6 \\
& Elementary education (6 yr of schooling) & 4.6 \\
& Secondary education (12 yr of schooling) & 33.5 \\
& University college (bachelor's degree) & 33.5 \\
& University degree (master's degree) & 10.5 \\
\hline
\end{tabular}

milk), farm milk (i.e., the whole process, from milking the cow to packaging the milk, is performed by the farmer), AA-milk (a Belgian quality label with specific hygiene requirements for farmers and milk processors), and conventional milk (defined as none of the above). Participants could also indicate "our family does not purchase milk" ( $\mathrm{n}=40)$, in which case they were excluded from the analysis (see inclusion criteria), resulting in 787 usable responses.

Attitudes Toward Dairy Cows. To measure attitudes toward dairy cows, participants were asked to score 13 items on 5 -point Likert scales $(1=$ fully disagree to $5=$ fully agree). These items were based on Austin et al. (2005), who investigated the attitudes of dairy farmers and agriculture students toward farm animal welfare. They found 5 (in farmers) and 6 (in students) factors with 2 superordinate dimensions labeled as natural living orientation and business orientation. These 2 dimensions strongly resemble the affect and utility dimensions defined in a review on this matter by Serpell (2004). Serpell argued that determinants of human attitudes toward animals and their welfare can be divided in 2 primary dimensions: affect (representing people's affective or emotional responses to animals, or both) and utility (representing people's responses to animals based on their instrumental value). We only report the survey items applicable to consumers and dairy cows (13 of 75 items in total used in the original survey by Austin et al., 2005). This includes statements about the cows' welfare, the farmer, and production goals (e.g., "cows have to be kept in an environment that is as natural as possible" and "a farmer should think of his/her cows mainly in terms of the profit they will bring in"; see Appendix Table A1). These items were deemed suitable for inclusion in the present study because they could be reduced to dimensions similar to those documented in previous studies (Serpell, 2004; Kauppinen et al., 2012; Kling-Eveillard et al., 2015). Some of the statements used for the present study were rephrased from Austin et al. (2005) to make them applicable to consumers (see Appendix Table A1).

General Attitudes Toward Milk and the Milk Industry. General attitudes toward milk and the milk industry were scored on 5-point semantic differential scales based on Sparks and Guthrie (1998). For attitude toward milk, the bipolar adjectives were unhealthy/ healthy, not essential/essential, not tasty/tasty, expensive/cheap, old-fashioned/modern, and negative/ positive. For the milk industry, the bipolar adjectives were unjust/just, negative/positive, not sustainable/ sustainable, and not transparent/transparent.

Associations Between Animal Welfare and Other Product Attributes. To assess consumers' associations of animal-friendly milk with other product attributes, participants were probed for their level of agreement with the statement "More attention for dairy cow welfare will lead to milk that is..." for 12 attributes in line with Vanhonacker et al. (2010). These attributes were more traditional, safer, of better quality, more hygienic, more authentic, easier to get, tastier, better for the environment, cheaper, healthier, more acceptable for me, and more profitable for the producer. Each of these characteristics was evaluated on a 5 -point Likert scale ranging from $1=$ fully disagree to $5=$ fully agree.

Product Attribute Importance. The product attribute importance was measured using the question: "When purchasing milk, how important are the following product attributes for you?" and registered on a 5 -point interval scale ranging from $1=$ totally unimportant to $5=$ very important. Attributes were: quality, food safety, freshness, healthiness, price, packaging, taste, sustainability, production method, animal wel- 
fare, local production, country of origin, environmental friendliness, and fair trade (based on Vanhonacker et al., 2010).

\section{Statistical Analysis}

Data were analyzed using SPSS 22 (Chicago, IL). Factor analysis using principal components was performed for each of the following 5 sets of measures: (1) attitudes toward dairy cows, (2) general attitudes toward milk, (3) general attitudes toward the milk industry, (4) associations between animal welfare and other product attributes, and (5) product attribute importance. Items were excluded using backward selection when factor scores were lower than 0.6 and when the item loaded high ( $>$ half of the highest) on 2 or more factors, as recommended by Field (2009). Cronbach's alphas were checked and deemed acceptable when higher than 0.7.

Paired $t$-tests were performed to determine differences between the perceived importance of product attributes using $P<0.05$ as a cut-off value for significance. Linear regression analysis was performed with intention to purchase animal-friendly milk as the dependent variable. Initial explanatory variables were socio-demographics variables (age, sex, education, and region), frequency of milk consumption, type of milk consumed, and factors of the attitudes toward dairy cows, general attitudes toward milk and the milk industry, associations with other product attributes, and product attribute importance.

The data complied with all assumptions for linear regression (i.e., normality of the residuals, heteroscedasticity, linearity, and multicollinearity using Spearman correlation index and variance inflation factor values). In line with Field (2009), outliers were detected using standardized residual values $(>3.29)$, covariance statistics (based on sample size, $>1.026$ and $<0.973$ ) and Cook's distance $(>1)$. Outliers were removed $(\mathrm{n}=$ 46) and components that had resulted from principal component analyses were checked for consistency after removal of the outliers. The final model was chosen using backward selection, excluding explanatory variables expressing a $P$-value $>0.10$.

\section{RESULTS}

\section{Milk Consumption}

Most participants consumed milk at least once per day $(54.1 \%)$, or multiple times per week $(27.3 \%)$. The majority of the participants consumed conventional milk $(65.1 \%)$ or AA-milk (22.6\%). A small percentage of people consumed farm milk (5.0\%), fair trade milk
$(4.2 \%)$, or organic milk $(3.2 \%)$. On average, the most important milk attributes were freshness and safety (mean importance scores of 4.19 and 4.17, respectively; Figure 1). Generally, the participants allocated about as much importance to animal welfare as to price (both rather important). More than half of the study participants expressed a positive intention to purchase animal-friendly milk (52.5\% agree or fully agree), whereas a small group answered negatively ( $7.3 \%$ disagree or fully agree).

\section{Attitudes Toward Dairy Cows}

Factor analysis on the 13 items revealed 3 factors (Table 2), which we labeled as business orientation, natural living orientation, and functioning orientation. The factor business orientation (Cronbach's $\alpha$, $\alpha=0.83)$ incorporated items concentrating on the economic function of cows for a farmer. The natural living orientation $(\alpha=0.73)$ contained items about natural behavior and the cows' living environment. The functioning orientation consisted of statements in which good animal welfare is closely associated with a cow's health status and performance $(\alpha=0.81)$. Mean scores $( \pm \mathrm{SD})$ were $2.60( \pm 0.63)$ for the factor business orientation, $4.10( \pm 0.76)$ for natural living orientation, and $3.35( \pm 0.74)$ for functioning orientation.

\section{General Attitude Toward Milk and the Milk Industry}

Factor analysis revealed that all descriptors for attitude toward milk loaded on one factor (total variance explained: $70.2 \%, \alpha=0.85$ ), except for the items "expensive versus cheap" and "old fashioned versus modern," which were excluded because factor loadings were too low (0.43 and 0.57). The items of attitude toward the milk industry could all be fit into one factor (total variance explained: $73.2 \%, \alpha=0.88$ ). Mean scores $( \pm \mathrm{SD})$ were $4.03( \pm 0.77)$ for general attitude toward milk and $2.97( \pm 0.82)$ for general attitude toward the milk industry.

\section{Associations Between Animal Welfare and Other Product Attributes}

Factor analysis identified 2 factors, explaining $62.4 \%$ of the total variance in associations between animal welfare and other product attributes. The first factor, perceived benefits, included items related to health, quality, taste, hygiene, acceptability, safety, authenticity, environmental friendliness, and traditionality $(\alpha$ $=0.91$ ). The second factor, perceived disadvantages, included items related to price, availability, and profit- 


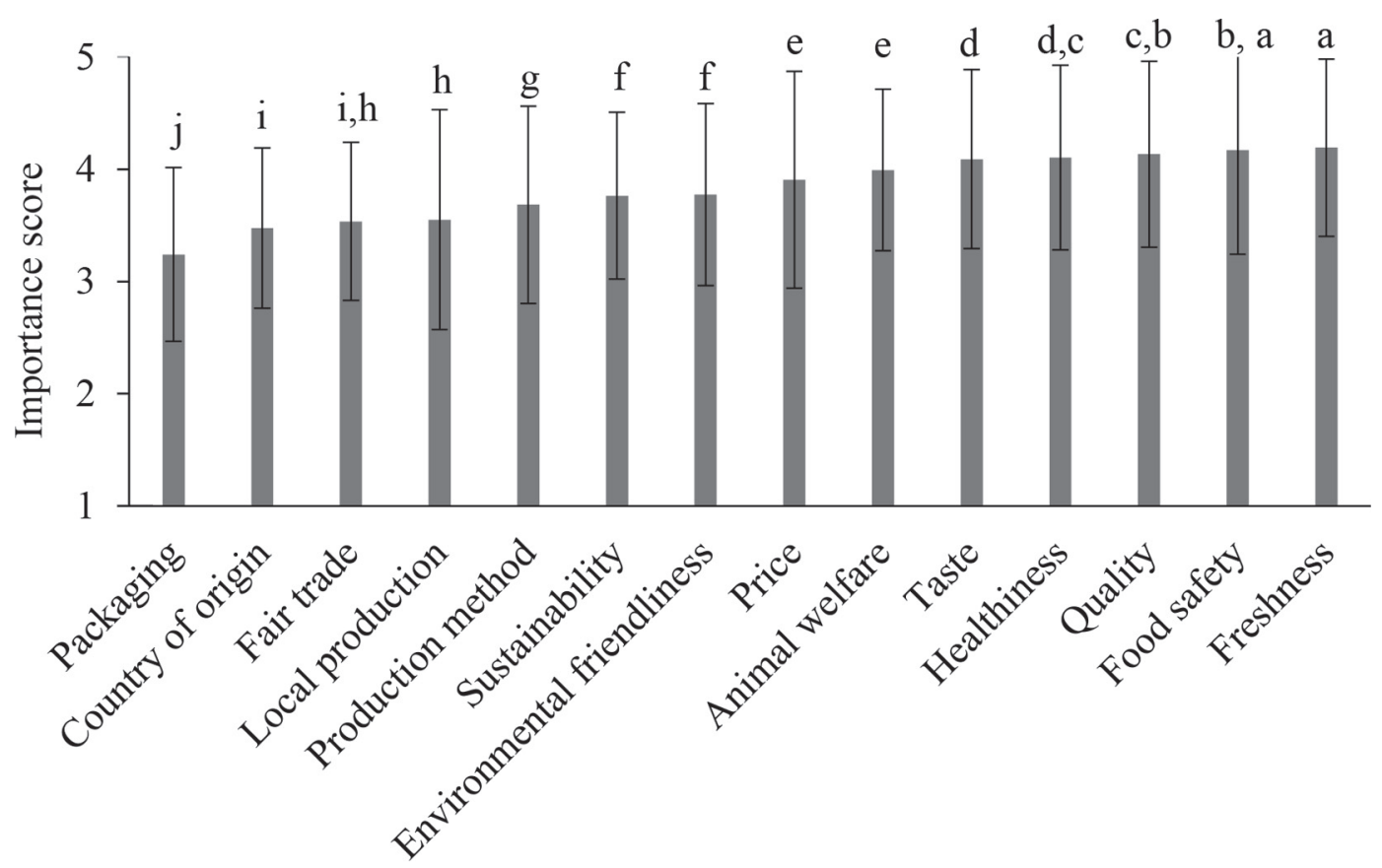

Product attributes

Figure 1. Product attribute importance of milk (mean attribute scores \pm SD) for the question "When purchasing cow's milk, how important are the following product attributes for you?" measured using a 5 -point interval scale ranging from $1=$ totally unimportant to $5=$ very important $(\mathrm{n}=787)$. Different letters $(\mathrm{a}-\mathrm{j})$ indicate significant differences (paired $t$-tests, $P<0.05)$.

ability for the farmer $(\alpha=0.69)$. Mean scores $( \pm \mathrm{SD})$ were for perceived benefits $(3.79 \pm 0.61)$ and perceived disadvantages $(3.08 \pm 0.69)$.

\section{Product Attribute Importance}

Factor analysis identified 2 factors explaining $66 \%$ of the total variance in perceived product attribute im- portance. The first factor, intrinsic product attributes, included the attributes quality, freshness, food safety, healthiness, and taste $(\alpha=0.91)$. The second factor, extrinsic product attributes, included local production, country of origin, packaging, and fair trade $(\alpha=0.71)$. This grouping of product attributes was based on a study by Olson and Jacoby (1972), who stated that intrinsic attributes are specific to each product and are

Table 2. Rotated factor loadings of the principal factor analysis of the attitudes toward cows and cow welfare, with 3 factors (F1-F3) labeled business orientation, natural living orientation, and functioning orientation $(\mathrm{n}=787)$

\begin{tabular}{|c|c|c|c|}
\hline Item $^{1}$ & $\begin{array}{l}\text { F1: Business } \\
\text { orientation }\end{array}$ & $\begin{array}{l}\text { F2: Functioning } \\
\text { orientation }\end{array}$ & $\begin{array}{l}\text { F3: Natural living } \\
\text { orientation }\end{array}$ \\
\hline $\begin{array}{l}\text { A farmer should think of his/her stock mainly in terms of their market value } \\
\text { or cost }\end{array}$ & $0.86^{2}$ & 0.06 & -0.24 \\
\hline $\begin{array}{l}\text { A farmer should view his/her cows as useful objects with which he can gain } \\
\text { personal benefit }\end{array}$ & 0.78 & 0.07 & -0.11 \\
\hline If a cow is reproducing efficiently, her welfare standards must be good & 0.03 & 0.88 & 0.08 \\
\hline If a cow is growing well she must be experiencing good welfare & 0.22 & 0.78 & -0.00 \\
\hline Cows need a natural habitat just as much as wildlife does & -0.17 & -0.00 & 0.82 \\
\hline Cows have to be kept in an environment that is as natural as possible & -0.10 & 0.04 & 0.81 \\
\hline It is important for cows to be able to express natural behavior & -0.30 & 0.16 & 0.73 \\
\hline
\end{tabular}

${ }^{1}$ Total variance explained: $69.1 \%$.

${ }^{2}$ Boldface type indicates items and their loading that are included in each factor. 
Table 3. Descriptive statistics (mean and SD) of dependent and explanatory variables (linear regression model, $\mathrm{n}=741$ )

\begin{tabular}{lcc}
\hline Variable & Mean & SD \\
\hline Dependent variable & 3.61 & 0.85 \\
Intention to purchase animal-friendly milk & 4.05 & 0.79 \\
Explanatory variable & 2.60 & 0.63 \\
Attitude toward milk & 4.10 & 0.76 \\
Attitudes toward dairy cows-Business orientation & 3.84 & 0.61 \\
Attitudes toward dairy cows-Natural living orientation & 3.91 & 0.82 \\
Associations with other product attributes-Benefits & 4.00 & 0.84 \\
Product attribute importance-Price & 3.53 & 0.72 \\
Product attribute importance-Animal welfare & & \\
Product attribute importance factor-Extrinsic product attributes &
\end{tabular}

no longer present when it is consumed and cannot be changed without changing the product itself. Extrinsic attributes are not physically a part of the product but are strongly associated with it (e.g., production method). Mean importance scores $( \pm \mathrm{SD})$ were $4.14( \pm 0.63)$ for intrinsic product attributes and $3.45( \pm 0.71)$ for extrinsic product attributes.

The attributes sustainability, price, and animal welfare could not be fit into either of the factors due to a high factor loading on both factors. However, in this study price and animal welfare were very important. We therefore chose to include these in the linear regression model as single-item explanatory variables.

\section{Linear Regression Results}

A significant correlation (correlation coefficient $>0.4$ ) was found between the factor of attitude toward dairy cows "functioning orientation," and the factor "intrinsic attribute importance"; therefore, the latter was excluded from analysis. Descriptive statistics of the variables are presented in Table 3.

The final linear regression model (Table 4) shows that the intention to purchase animal-friendly milk was positively influenced by (1) higher perceived benefits from animal-friendly milk in terms of the product being perceived as healthier, of better quality, tastier, more hygienic, more acceptable, safer, more authentic, environmentally friendlier, and more traditional; (2) a higher personal importance attached to extrinsic product attributes (local production, country of origin, packaging, and fair trade); (3) a higher personal importance attached to the product attribute "animal welfare," (4) a higher score for the attitude toward dairy cows of "natural living orientation," and (5) a more positive attitude toward milk. Intention was negatively influenced by (1) a higher score for the attitude toward dairy cows of "business orientation" and (2) a higher personal importance of the attribute price. Neither the socio-demographic characteristics (i.e., sex, age, education, region), nor the behavioral characteristics such as milk consumption frequency or type of milk consumed, expressed a $P$-value $<0.10$, and these were therefore not included in the final model. The final model explained $42.4 \%\left(\mathrm{R}^{2}\right)$ of the variation in the intention to purchase animal-friendly milk.

\section{DISCUSSION}

The goals of this study were to gain insight into consumers' intention to purchase animal-friendly milk, and to explore attitudes and perceptions that influence this purchase intention. The study complements previous studies by focusing on the welfare of a specific species

Table 4. Determinants of the intention to purchase animal-friendly milk (linear regression model, $\mathrm{n}=741$ )

\begin{tabular}{|c|c|c|c|c|}
\hline \multirow[b]{2}{*}{ Variable } & \multirow{2}{*}{$\begin{array}{c}\text { Standardized } \\
\beta\end{array}$} & \multirow[b]{2}{*}{$P$-value } & \multicolumn{2}{|c|}{$95.0 \%$ CI for $\beta$} \\
\hline & & & Lower bound & Upper bound \\
\hline Product attribute importance factor - extrinsic product attributes & 0.22 & $<0.001$ & 0.18 & 0.34 \\
\hline Associations with other product attributes - benefits & 0.21 & $<0.001$ & 0.18 & 0.39 \\
\hline Attitudes toward dairy cows - natural living orientation & 0.19 & $<0.001$ & 0.10 & 0.22 \\
\hline Product attribute importance - animal welfare & 0.18 & $<0.001$ & 0.10 & 0.25 \\
\hline Attitudes toward dairy cows - business orientation & -0.17 & $<0.001$ & -0.19 & -0.09 \\
\hline Product attribute importance - price & -0.17 & $<0.001$ & -0.24 & -0.12 \\
\hline Attitude toward milk & 0.06 & 0.049 & 0.00 & 0.13 \\
\hline
\end{tabular}


(i.e., dairy cows), and on a particular food product category (i.e., cow milk). These insights may therefore be valuable in formulating recommendations for producers or retailers (or both) aiming to market animal-friendly milk.

A heterogeneous intention to purchase animal-friendly milk was found in our study, where a majority (52.5\%) expressed a positive intention. Although these percentages are based on self-reporting, and therefore potentially overestimated, they suggest a substantial market interest and preference for animal-friendly milk. The heterogeneity in intention to purchase animal-friendly products has also been reported in earlier studies (e.g., Vanhonacker and Verbeke, 2009; Verbeke et al., 2010; de Jonge and van Trijp, 2013, 2014). However, the market for milk products is at present poorly differentiated in terms of animal welfare in Belgium. Therefore, a deeper understanding of determinants that influence intention to purchase animal-friendly milk can be relevant.

Corresponding with the TPB, our results showed a significant relationship between attitudes and intention. Intention to purchase was positively influenced by a more natural living oriented attitude toward cows, in line with Vanhonacker et al. (2010), and a more positive general attitude toward milk. By contrast, we found intention to be negatively influenced by a stronger business-oriented attitude toward cows. This corroborates with findings by Vanhonacker et al. (2007) in which a segment of consumers with a business-oriented view on farm animals was identified, which also had a lower intention to purchase animal-friendly products.

Similar to attitudes, we found different product attribute perceptions to significantly influence the intention to purchase animal-friendly milk. The evaluation of food products is a multi-attribute decision process (Fishbein, 1967). Previous studies reported that a higher priority is generally given by consumers to intrinsic product attributes such as quality, health, and safety than to aspects related to moral and sustainability issues such as fair trade, local production, and animal welfare (Ingenbleek et al., 2006; Vanhonacker et al., 2010). This was confirmed for the pooled sample in the current study, where on average intrinsic rather than extrinsic product attributes were given the highest importance score. However, looking beyond the pooled sample averages, results suggested some degree of heterogeneity in perceived product attribute importance. Namely, participants who attached a higher importance to extrinsic product attributes were found to have a stronger intention to purchase animal-friendly milk, whereas participants who indicated a higher personal importance attached to price showed a weaker intention to purchase animal-friendly milk. These results are consistent with findings by Vanhonacker and Verbeke (2009) on the choice for animal-friendly poultry products.

Furthermore, we found price and animal welfare as product attributes to be rated equally important in our sample. This is in contrast with many earlier studies where price was considered more important to consumers than animal welfare (e.g., Harper and Henson, 2001; Vanhonacker et al., 2010). This might be an effect of the growing concern and interest in animal welfare among European consumers, as illustrated by the Eurobarometer studies from different years (European Commission, 2007,2016 ). However, in other survey-based consumer studies, some social desirability bias may have led to an underestimation of the importance of price versus an overestimation of the importance of animal welfare. This was illustrated by Wolf et al. (2016) where participants generally indicated that they found animal welfare more important than low milk prices but also indicated that they thought the "average American" would not necessarily agree. These authors argue that due to social desirability bias responses projected on the average American are probably closer to the actual attitudes of the respondents.

Even though, generally, price and animal welfare were considered to be of equal importance in our study sample, not all consumers will be attracted to the highest level of animal welfare (Vermeir and Verbeke, 2006; Vanhonacker et al., 2007), but intermediate levels of price and animal welfare might suit the Flemish market for animal-friendly milk. de Jonge et al. (2015) labeled such intermediate products (broiler filets in their study) as "compromise products" and van Herpen et al. (2015) referred to these (meat products) as "mildly sustainable" products. de Jonge et al. (2015) reported that the consumption of animal friendly meat products increased when such compromise products are offered in the assortment. van Herpen et al. (2015) reported similar results but added nuance to their findings by adding that in-store display and price level influence product choice. Further studies could focus on market segmentation for animal-friendly milk specifically, and on identifying characteristics of different segments.

Results of the current study give some insight on how to communicate about animal-friendly milk. Opportunities for communication stem from the finding that the intention to purchase animal-friendly milk was related to other product attributes in the factor "benefits" (in terms of the animal-friendly product being perceived as healthier, of higher quality, tastier, more hygienic, more acceptable, safer, more authentic, more environmentally friendly, and more traditional). This indicates that the participants who were more likely 
to purchase animal-friendly milk also associated other benefits more strongly with animal welfare. This is in accordance with earlier studies by Vanhonacker and Verbeke (2009) and Cardoso et al. (2016) who found that people related higher welfare standards with product attributes such as health, taste, and quality. We conclude from these findings that communication to promote animal-friendly milk does not necessarily have to focus on highlighting the welfare of the cows only, but could also highlight the associated benefits of the resulting milk and dairy products. This could attract a wider group of consumers. To use such benefit claims, further research might be needed to evidence the link between animal welfare and other product benefits, such as for example indications of a positive relationship between animal welfare and milk quality (Müller-Lindenlauf et al., 2010) or a higher nutritional quality in products that originate from organic dairy farms (Palupi et al., 2012).

In contrast to attitudes and perceptions, intention to purchase animal-friendly milk was neither significantly related to socio-demographic factors (such as sex and age) nor to behavioral characteristics (such as frequency and type of milk consumed) when analyzed in a multivariate setting together with attitudinal factors. In fact, earlier studies also questioned the usefulness of socio-demographic or behavioral factors (or both) in food-related decisions involving ethical considerations (Diamantopoulos et al., 2003; Vanhonacker and Verbeke, 2009).

\section{Limitations and Future Research}

Every study is based on a specific research design and applies certain methodologies and analyses. This choice imposes some limitations, providing at the same time challenges for future research. This study was developed to gain first insights in determinants that influence consumers' intention to purchase animal-friendly milk. We mainly focused on attitudes, applying Ajzen's TPB to measure attitudes toward dairy cows based on Austin et al. (2005). These questions were mainly gauging specific elements of welfare instead of the entirety of dairy cattle welfare, particularly toward natural living, but paid less attention to other elements of animal welfare such as biological functioning and affective state (Fraser et al., 1997). Further research could study more and/or other possible attitudinal determinants, or other constructs such as beliefs, life-style variables, or values.

Further, we have used a structured questionnaire and survey method, which has the advantage to collect data from a large number of participants, allowing quantitative analyses. Its disadvantage is potential bias induced by the hypothetical nature of the survey and a possible social desirability bias (Fisher and Katz, 2000). Given the debated relationship between what an individual states as a citizen and how he/she actually behaves as a consumer (Vermeir and Verbeke, 2006), further research is recommended to validate the findings of this study in nonhypothetical research settings. Finally, further research could study whether the findings are applicable for animal products from other animal species and in other geographical regions or specific (consumer) population groups.

\section{CONCLUSIONS}

This study showed that adult Flemish (Belgian) milk consumers varied in their self-reported intention to purchase animal-friendly milk, with a small majority indicating a positive intention. This variation was (partly) explained by the perceived benefits from animal-friendly milk, the importance attached to extrinsic product attributes, the importance of animal welfare and price as a product attribute, the natural living oriented and business-oriented attitudes toward dairy cows, and the attitude toward milk. These results can be used to position animal-friendly milk on the market. The finding that various determinants positively influence intention to purchase, such as highlighting the welfare of the cows along with the associated benefits of such a product, can be used in communication about animal-friendly milk, to address specific consumers' beliefs and desires.

\section{ACKNOWLEDGMENTS}

The authors thank Miriam Levenson (Institute for Agricultural and Fisheries Research, Belgium) for language editing. We also thank the Institute for Agricultural and Fisheries Research (ILVO) personnel who helped to pre-test the questionnaire.

\section{REFERENCES}

Ajzen, I. 1985. From Intentions to Actions: A Theory of Planned Behavior. Springer, Berlin Heidelberg, Germany.

Austin, E. J., I. J. Deary, G. Edwards-Jones, and D. Arey. 2005. Attitudes to farm animal welfare: factor structure and personality correlates in farmers and agriculture students. J. Individ. Differ. $26: 107-120$.

Buller, H., and C. Cesar. 2007. Eating well, eating fare: Farm animal welfare in France. Int. J. Soc. Food Agric. 15:45-58.

Cardoso, C. S., M. J. Hötzel, D. M. Weary, J. A. Robbins, and M. A. von Keyserlingk. 2016. Imagining the ideal dairy farm. J. Dairy Sci. 99:1663-1671.

de Jonge, J., I. A. van der Lans, and H. C. van Trijp. 2015. Different shades of grey: Compromise products to encourage animal friendly consumption. Food Qual. Prefer. 45:87-99.

de Jonge, J., and H. C. van Trijp. 2013. Meeting heterogeneity in consumer demand for animal welfare: A reflection on existing 
knowledge and implications for the meat sector. J. Agric. Environ. Ethics 26:629-661.

de Jonge, J., and H. C. van Trijp. 2014. Heterogeneity in consumer perceptions of the animal friendliness of broiler production systems. Food Policy 49:174-185.

de Vries, M., E. A. M. Bokkers, C. G. Van Reenen, B. Engel, G. van Schaik, T. Dijkstra, and I. J. M. de Boer. 2015. Housing and management factors associated with indicators of dairy cattle welfare. Prev. Vet. Med. 118:80-92.

Diamantopoulos, A., B. B. Schlegelmilch, R. R. Sinkovics, and G. M. Bohlen. 2003. Can sociodemographics still play a role in profiling green consumers? A review of the evidence and an empirical investigation. J. Bus. Res. 56:465-480.

European Commission. 2007. Attitudes of EU citizens towards animal welfare. Special Eurobarometer 270. Accessed March 2016. http:// www.vuzv.sk/DB-Welfare/vseob/sp_barometer_aw_en.pdf.

European Commission. 2016. Attitudes of Europeans towards Animal Welfare. Special Eurobarometer 442. Accessed March 2016. http://ec.europa.eu/COMMFrontOffice/PublicOpinion/index. cfm/ResultDoc/download/DocumentKy/71348.

Field, A. 2009. Discovering statistics using SPSS. 3rd ed. Sage Publications, London, UK.

Fishbein, M. 1967. A behavior theory approach to the relations between beliefs about an object and the attitude toward the object. Pages 389-400 in Readings in attitude theory and measurement. M. Fishbein ed., Wiley, New York, NY.

Fishbein, M., and I. Ajzen. 2010. Predicting and Changing Behavior: The Reasoned Action Approach. Taylor \& Francis, New York, NY.

Fisher, R. J., and J. E. Katz. 2000. Social-desirability bias and the validity of self reported values. Psychol. Mark. 17:105-120.

Fraser, D., D. M. Weary, E. A. Pajor, and B. N. Milligan. 1997. A scientific conception of animal welfare that reflects ethical concerns. Anim. Welf. 6:187-205.

Grunert, K. G., L. Bredahl, and K. Brunsø. 2004. Consumer perception of meat quality and implications for product development in the meat sector-A review. Meat Sci. 66:259-272.

Harper, G., and S. Henson. 2001. Consumer concerns about animal welfare and the impact on food choice. EU FAIR CT98-3678, Centre for Food Economics Research, The University of Reading.

Heleski, C. R., A. G. Mertig, and A. J. Zanella. 2004. Assessing attitudes toward farm animal welfare: A national survey of animal science faculty members. J. Anim. Sci. 82:2806-2814.

Holm, L., and M. Møhl. 2000. The role of meat in everyday food culture: An analysis of an interview study in Copenhagen. Appetite 34:277-283.

Ingenbleek, P. T. M., M. H. A. Binnekamp, and J. C. M. van Trijp. 2006. Betalen voor dierenwelzijn: barriëres en oplossingsrichtingen in consumentenmarkten en business-to-business markten. LEI, Wageningen, the Netherlands.

Kauppinen, T., K. M. Vesala, and A. Valros. 2012. Farmer attitude toward improvement of animal welfare is correlated with piglet production parameters. Livest. Sci. 143:142-150.

Kennedy, O. B., B. J. Stewart-Knox, P. C. Mitchell, and D. I. Thurnham. 2004. Consumer perceptions of poultry meat: A qualitative analysis. Nutr. Food Sci. 34:122-129.

Kling-Eveillard, F., U. Knierim, N. Irrgang, F. Gottardo, R. Ricci, and A. C. Dockès. 2015. Attitudes of farmers towards cattle dehorning. Livest. Sci. 179:12-21.

Mejdell, C. M. 2006. The role of councils on animal ethics in assessing acceptable welfare standards in agriculture. Livest. Sci. 103:292296.

Müller-Lindenlauf, M., C. Deittert, and U. Köpke. 2010. Assessment of environmental effects, animal welfare and milk quality among organic dairy farms. Livest. Sci. 128:140-148.

Olson, J. C., and J. Jacoby. 1972. Cue utilization in the Quality Perception Process. Pages 167-179 in Proceedings of the Third An- nual Conference of the Association for Consumer Research, Iowa City. Association for Consumer Research, Duluth, MN.

Oosterkamp, E. B., B. Bremmer, R. Hoste, and K. H. De Greef. 2011. Verkenning van dierlijke tussensegmenten in onze buurlanden; Duurzaam varkensvlees, pluimveevlees en eieren. LEI, Wageningen UR, Wageningen, the Netherlands.

Palupi, E., A. Jayanegara, A. Ploeger, and J. Kahl. 2012. Comparison of nutritional quality between conventional and organic dairy products: A meta-analysis. J. Sci. Food Agric. 92:2774-2781.

Samborski, V., and L. Van Bellegem. 2016. De biologische landbouw in Vlaanderen: stand van zaken 2015. Departement Landbouw en Visserij, Brussels, Belgium.

Serpell, J. A. 2004. Factors influencing human attitudes to animals and their welfare. Anim. Welf. 13:145-151.

Sparks, P., and C. A. Guthrie. 1998. Self-identity and the theory of planned behavior: A useful addition or an unhelpful artifice? J. Appl. Soc. Psychol. 28:1393-1410.

Taylor, N., and T. D. Signal. 2009. Willingness to pay: Australian consumers and 'on the farm' welfare. J. Appl. Anim. Welf. Sci $12: 345-359$

te Velde, H., N. Aarts, and C. Van Woerkum. 2002. Dealing with ambivalence: Farmers' and consumers' perceptions of animal welfare in livestock breeding. J. Agric. Environ. Ethics 15:203-219.

van Herpen, E., A. R. Fischer, and H. C. van Trijp. 2015. How to position 'mildly sustainable' products: The joint impact of assortment display and price setting. Food Qual. Prefer. 46:26-32.

Van Loo, E. J., V. Caputo, R. M. Nayga Jr., and W. Verbeke. 2014 Consumers' valuation of sustainability labels on meat. Food Policy 49:137-150.

Van Loo, E. J., M. N. H. Diem, Z. Pieniak, and W. Verbeke. 2013. Consumer attitudes, knowledge, and consumption of organic yogurt. J. Dairy Sci. 96:2118-2129.

Vanhonacker, F., E. Van Poucke, F. Tuyttens, and W. Verbeke. 2010 Citizens' views on farm animal welfare and related information provision: Exploratory insights from Flanders, Belgium. J. Agric. Environ. Ethics 23:551-569.

Vanhonacker, F., and W. Verbeke. 2009. Purchasing higher welfare poultry products? Profiling Flemish consumers who do and do not. Poult. Sci. 88:2702-2711.

Vanhonacker, F., and W. Verbeke. 2014. Public and consumer policies for higher welfare food products: Challenges and opportunities. J. Agric. Environ. Ethics 27:153-171.

Vanhonacker, F., W. Verbeke, E. Van Poucke, and F. A. M. Tuyttens. 2007. Segmentation based on consumers' perceived importance and attitude toward farm animal welfare. Int. J. Sociol. Agric. Food 15:91-107.

Verbeke, W. 2005. Agriculture and the food industry in the information age. Eur. Rev. Agric. Econ. 32:347-368.

Verbeke, W. 2009. Stakeholder, citizen and consumer interests in farm animal welfare. Anim. Welf. 18:325-333.

Verbeke, W., F. J. Pérez-Cueto, M. D. de Barcellos, A. Krystallis, and K. G. Grunert. 2010. European citizen and consumer attitudes and preferences regarding beef and pork. Meat Sci. 84:284-292.

Vermeir, I., and W. Verbeke. 2006. Sustainable food consumption: Exploring the consumer attitude-behavioral intention. J. Agric. Environ. Ethics 19:169-194.

von Keyserlingk, M. A. G., A. Barrientos, K. Ito, E. Galo, and D. M. Weary. 2012. Benchmarking cow comfort on North American freestall dairies: Lameness, leg injuries, lying time, facility design, and management for high-producing Holstein dairy cows. J. Dairy Sci. 95:7399-7408.

Wolf, C. A., G. T. Tonsor, M. G. S. McKendree, D. U. Thomson, and J. C. Swanson. 2016. Public and farmer perceptions of dairy cattle welfare in the United States. J. Dairy Sci. 99:5892-5903. http:// dx.doi.org/10.3168/jds.2015-10619. 


\section{APPENDIX}

Table A1. The items for attitudes toward dairy cows as used in the current study, adjusted from Austin et al. (2005)

Item

Cows have to be kept in an environment that is as natural as possible.

It is important for cows to be able to express natural behavior.

Seeing a neglected cow doesn't affect me as much as it would affect most people.

The idea of a "natural environment" applies to farm animals as well as wild animals.

Production efficiency should be first priority of the farmer.

A farmer should think of his/her cows mainly in terms of the profit they will bring in.

A farmer should think of his/her cows mainly in terms of their market value or cost.

A farmer should view his/her animals as useful objects with which he/she could gain profit.

I tend to think of cows as being very similar to machines.

A cow that is physically fit experiences good welfare by definition.

If a cow is reproducing efficiently her welfare standards must be good.

If a cow is growing well she must be experiencing good welfare.

A cow that is physically healthy cannot be suffering. 